\title{
HISTOLOGICAL FEATURE OF OVARIAN STRUCTURES THROUGHOUT THE REPRODUCTIVE CYCLE IN ALPINE GOATS (CAPRA HIRCUS)
}

\author{
Debora Groppetti ${ }^{1}$, Alessandro Pecile ${ }^{1}$, Stefano Frattini ${ }^{1}$, \\ Giulio Pagnacco ${ }^{1}$, Silvana Arrighi ${ }^{2}$ \\ ${ }^{1}$ Department of Veterinary Medicine, Faculty of Veterinary Medicine, \\ University of Milan, 10, via G. Celoria - 20133 Milan, Italy \\ ${ }^{2}$ Department of Health, Animal Science and Food Safety, Laboratory of Anatomy, \\ Faculty of Veterinary Medicine, University of Milan, 2, \\ via Trentacoste - 20134 Milan, Italy
}

Received 4 February 2018; Received in revised form 17 May 2018; Accepted 27 August 2018

\begin{abstract}
The knowledge about ovarian physiology in small ruminants is still limited, especially when compared to other domestic species. Ovarian function in goats is mainly assessed by ultrasonographic techniques, whereas a quali-quantitative feature of the follicular and luteal structures throughout the reproductive cycle in naturally cycling goats is scarce. This study provides a detailed description of the functional morphology and size of 742 ovarian structures (follicles, corpora hemorrhagica and corpora lutea) in relation to the oestrus phase, the body weight and the age of 25 Alpine goats (Capra hircus). The current study demonstrated that, the number and size of the follicles were related to the stage of the reproductive cycle $(\mathrm{P}<0.0001)$. Also, the mean number of follicles was high during both prepubertal anestrus and diestrus, whereas it was low in the oestrus. Large (3-4 mm in diameter) and very large follicles $(>4 \mathrm{~mm})(\mathrm{P}<0.001)$, and small follicles $(<2 \mathrm{~mm} ; \mathrm{P}<0.05)$ varied throughout the reproductive cycle, while medium follicles $(2-3 \mathrm{~mm})$ were invariably observed. Large and very large follicles were predominant during the diestrus phase and small follicles in the prepubertal anestrus. It is evident from the current study that the number of follicles $(\mathrm{P}<0.05)$ was significantly affected with both body weight and age. On the other hand, the size of follicles was significantly affected with body weight only $(\mathrm{P}<0.0001)$. These results could contribute to a deeper understanding of ovarian transformations with important implications in assisted reproductive technologies, thereby concurring in advancing the efficiency of ultrasound in breeding programs for this species.
\end{abstract}

Key words: goat; ovary; histology; reproductive cycle

\section{INTRODUCTION}

Small ruminants are an emerging species of zootechnical interest with an important economic role both for the recovery of mountain and rural semi-abandoned areas in developing countries, and for the dairy industry (milk and cheese), childhood nutrition and food intolerance in developed

Corresponding author: Dr. Debora Groppetti, $\mathrm{PhD}$

E-mail address: debora.groppetti@unimi.it

Present address: Department of Veterinary Medicine,

Faculty of Veterinary Medicine, University of Milan, 10,

via G. Celoria - 20133 Milan, Italy

Phone: ++39-02-503-18151; Fax: +39-02-503-18148

Copyright: (C) 2018 Groppetti D. This is an open-access article published under the terms of the Creative Commons Attribution License which permits unrestricted use, distribution, and reproduction in any medium, provided the original author and source are credited.

Competing Interests: The authors have declared that no competing interests exist.

Available Online First: 3 November 2018

Published on: 15 March 2019

https://doi.org/10.2478/macvetrev-2018-0027 countries. Understanding the physiological changes in the ovarian structures during the reproductive cycle is increasingly important for designing enhanced assisted reproductive technologies to progress the efficiency of breeding programs in domestic animals (1). An accurate prediction of the reproductive stage is mandatory for oestrus synchronisation or superovulatory treatments, even more for artificial insemination and advanced protocols of embryo production and transfer (2).

To date, reports on the morphometry of ovarian structures in naturally cycling goats are limited. Previous studies on ovarian activity in goats are based on laparotomy, laparoscopy or ultrasound techniques $(3,4)$. Ultrasound permits monitoring of ovarian evolution and follicular waves by successive observations $(5,6)$ and it represents a valid, practical and non-invasive method for clinical evaluation of the 
reproductive cycle. However, this technique requires daily repeated measurements and operator skills. On the other hand, the number of follicles could not be related to the stage of the reproductive cycle and the same could be done for follicular size as previously reported in sheep (7). Therefore, an accurate morphological description of the organisation, vascularization, as well as the number and size of the ovarian structures can improve the diagnostic potential of ultrasound technique in monitoring the reproductive cycle of goats.

This study intends to provide insight into the histological and histometric ovarian aspects along with hormonal outcomes, in order to optimize fertility management and the efficacy of breeding programs in this species. Histomorphometric characterizations of the ovarian changes occurring at precise phases of the natural unsynchronized reproductive cycle in goats were correlated with plasma progesterone concentrations, body weight and age.

\section{MATERIAL AND METHODS}

The present experiment is part of a large epigenetic project that conformed to ethical standards, under the approval of the Ethical Committee of the University of Milan. Animals in the study were transported, sacrificed and organs were collected according to the European Directive 2010/63/EU on the protection of animals used for scientific purposes.

\section{Animals and reproductive cycle monitoring}

Gonads were obtained during the breeding and non-breeding season from twenty-five healthy Alpine goats (Capra hircus), aged 2-12 months. The goats were housed in a dedicated shelter located in Northern Italy with free access to an external paddock, and fed alfalfa hay supplemented with a commercial concentrate. Clean water and mineralized salt licks were available ad libitum. The animals were kept under natural day length throughout the experimental period, that is from August 2014 to February 2015. Natural reproductive cycle onset was recorded without performing any hormonal treatment for oestrus synchronization.

Each goat was slaughtered at defined times as determined by the main project, that is $\mathrm{N}=5$ goats at prepubertal anestrus, $\mathrm{N}=4$ goats at proestrus, $\mathrm{N}=3$ goats at oestrus, $\mathrm{N}=8$ goats at diestrus, and $\mathrm{N}=5$ goats at anestrus. Both ovaries were immediately removed and referred to the laboratory for histomorphometric analysis. Ages and weights of the 25 goats at slaughtering were summarized in Table 1.

The attainment of puberty of the goats and, thereafter, the ovarian activity and oestrus cycle phase were established by progesterone determination and oestrus behaviour evaluation $(4,8,9,10)$. Plasma progesterone measurements were performed twice a week starting August 2014 up to February 2015. For a more precise evaluation at the time of gonad removal, an additional progesterone assessment was performed on the day of slaughtering. Blood samples were collected by jugular vein-puncture into heparinized tubes and centrifuged within $2 \mathrm{~h}$ after collection. Plasma was stored frozen at $-20^{\circ} \mathrm{C}$ until assayed for hormones. Plasma progesterone concentration (P4) was determined using a quantitative test based on the ELFA technique (Enzyme Linked Fluorescent Assay; MiniVidas ${ }^{\circledR}$, BioMérieux, France). Assay principle combines an enzyme immunoassay competition method with a final fluorescent detection (11).

Sexual behaviour was checked twice a day with a vasectomized buck throughout the experimental period. Oestrus was defined as the moment when the goat stands to be mounted by the vasectomized buck.

\section{Histology and histometry}

Immediately after slaughtering, the macroscopical aspect of both ovaries of each goat was accurately evaluated in order to record the number, dimension and structures present, including the number of tertiary follicles, corpora hemorrhagica (CHs) and corpora lutea (CLs). Ovaries were fixed by immersion in $10 \%$ neutral formalin for $48-72 \mathrm{~h}$ at $4^{\circ} \mathrm{C}$, then each gonad was further sectioned to identify and count ovarian structures in more detail. All the pieces were dehydrated in a graded series of ethanol, cleared with xylene and embedded in paraffin. Microtome sections $(4 \mu \mathrm{m})$ were de-waxed and stained with routinary Haematoxylin-Eosin (H\&E) for general morphological purposes and histometry. Sections were viewed under an Olympus BX51 microscope equipped with a digital camera and DP software (Olympus, Italy) for computer-assisted image acquisition and managing. Only tertiary vesicular follicles were considered for histometric purposes. These follicles were subdivided into four categories according to their diameter: small (SF, $<2 \mathrm{~mm}$ ), medium (MF, 2-3 mm), large (LF, 3-4 mm), and very large (XLF, $>4 \mathrm{~mm}$ ) follicles. Primordial, primary and secondary follicles were not considered in the morphometric study. The number and size of 
corpora hemorrhagica and mature corpora lutea were also recorded. Histometry was performed on micrographs taken on H\&E-stained sections. The diameter of the ovarian structures was measured in the largest cross section, with the theca interna as a limit. The highest magnification allowed by their individual dimensions was utilized, i.e. 40x objective for follicle diameter $<300 \mu \mathrm{m}, 20-10 \mathrm{x}$ for follicle diameter 300-1000 $\mu \mathrm{m}$ and $4 \mathrm{x}$ for follicle diameter $>1000 \mu \mathrm{m}$. For each ovary, all follicles having a diameter $>0.1 \mathrm{~mm}$ were recorded.

\section{Statistical analyses}

The data were analyzed using regular descriptive statistics (mean \pm standard deviation). Analysis of variance was performed using statistical fixed factors models (Proc Means and GLM, S.A.S.
2013), including both covariates (age and body weight of the goats) and class factors (reproductive phases). Differences were defined according to probability values, with significance threshold set as $\mathrm{P}<0.05$. Base SAS ${ }^{\circledR} 9.4$ Procedures Guide: Statistical Procedures, Second Edition. Cary, NC: Sas Institute Inc. 2013

\section{RESULTS}

A total of 742 ovarian structures (tertiary follicles, CHs and CLs) were examined in the 25 paired ovaries collected from 25 goats. Tertiary follicles from the right and left ovary were 363 and 379 , respectively. Very large follicles were monolaterally $(\mathrm{N}=15)$ recorded in 8 out of 18 goats, while the remaining 25 XLFs were bilaterally distributed.
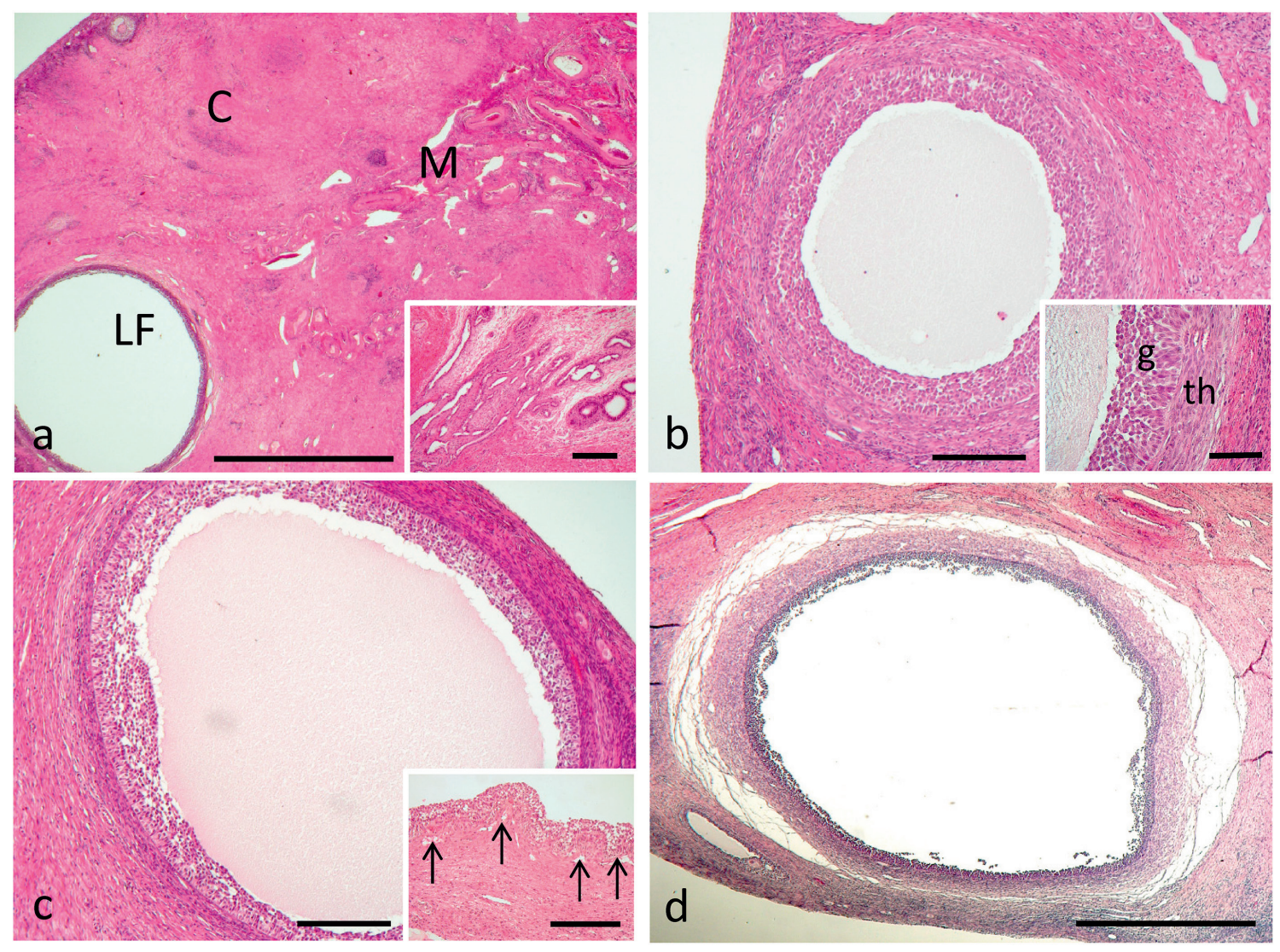

Figure 1. Usual organization of the goat ovaries into a cortical (C) and a medullar (M) ovarian zone. A large follicle (LF) can be seen. Inset: typical aspect of the rete ovarii, which was often seen in the medullary zone (a). Small follicle (SF) in the goat ovary. Inset: detail of the follicular wall. The typical aspect of granulosa (g) and inner theca (th) cells can be noticed. Blood vessels are abundant in the layer of inner theca closer to granulosa (b). Medium follicle (MF) in the goat ovary. Inset: notice the thick stratum of granulosa cells and well vascularized inner theca, separated by an evident and loopy basal membrane. Arrows indicate blood vessels (c). A medium follicle during goat anestrus shows typical signs of atresia. See text for details (d). Scale bars: a) $2000 \mu \mathrm{m}$; inset $300 \mu \mathrm{m}$; b) $300 \mu \mathrm{m}$; inset $100 \mu \mathrm{m}$; c) $300 \mu \mathrm{m}$; inset $200 \mu \mathrm{m}$; d) $1000 \mu \mathrm{m}$ 

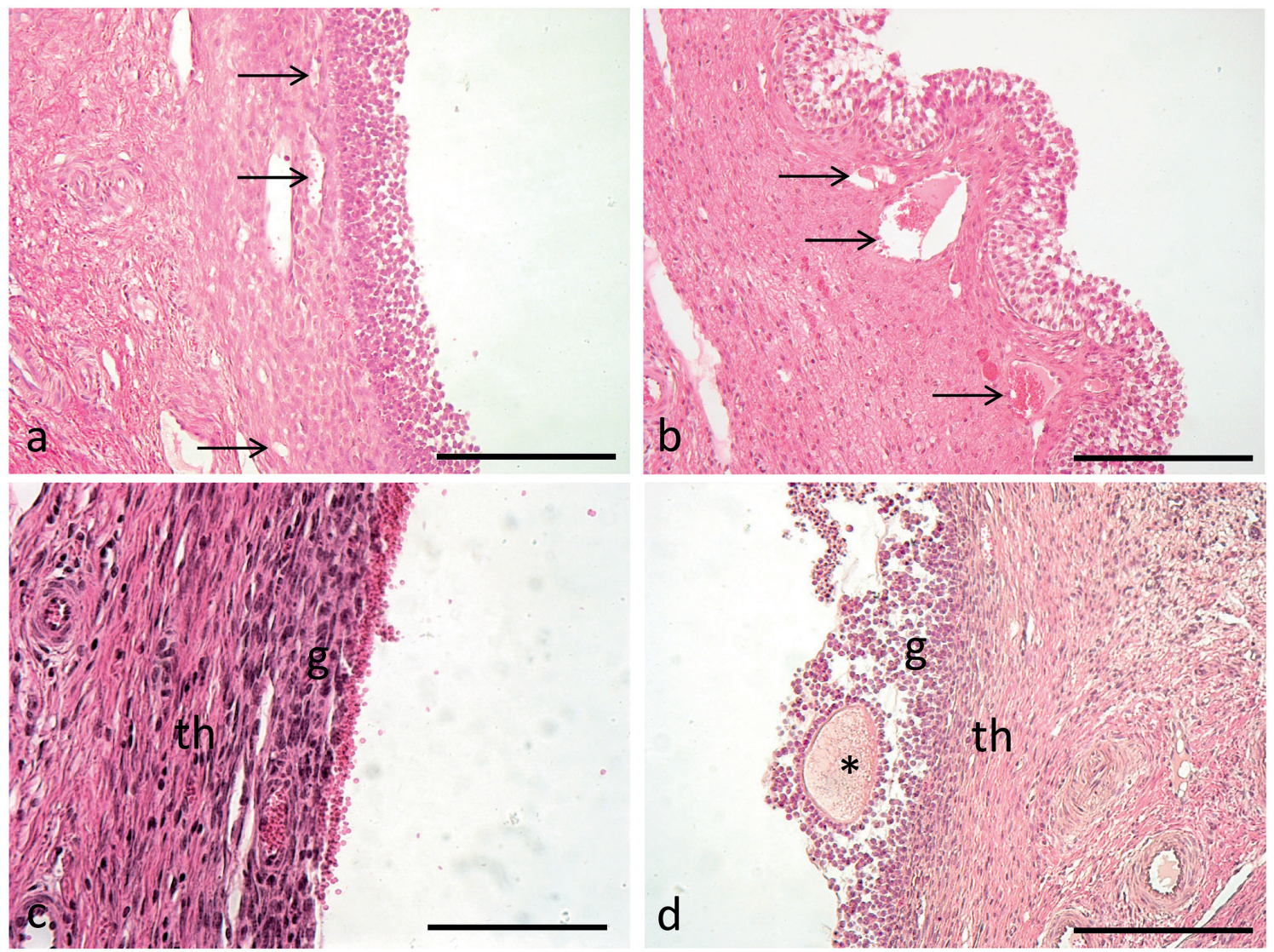

Figure 2. Aspect of the wall of a large follicle during prepuberal anestrus, showing well distinguishable granulosa and inner theca membranes, the latter well vascularized by a large number of capillaries (arrows) (a). Large follicle in goat ovary during proestrus, showing folded granulosa and massive vascularization of the follicular inner theca (arrows), whose cells are hypertrophic (b). In the periovulatory period the wall of a large follicle has flattened granulosa (g) and theca membranes (th), with indistinct boundary between them (c). During diestrus large and very large follicles show distinct granulosa and theca membranes and the inner theca is well vascularized. Asterisk indicates oocyte surrounded by zona pellucida (d). Scale bars: a,b,d) $200 \mu \mathrm{m}$; c) $100 \mu \mathrm{m}$

CHs and CLs were mono-laterally $(\mathrm{N}=10)$ recorded in 9 out of 11 goats with one goat having both two CLs from the same ovary, while in the remaining two goats $2 \mathrm{CHs}$ and $2 \mathrm{CLS}$ were bilaterally distributed.

\section{Histological morphology of the ovarian structures}

Prepubertal goats had very small (no more than $2 \mathrm{~cm}$ long) oval shaped ovaries with a smooth surface. The outer cortex contained dense, evenly distributed primordial follicles. In the inner cortex, primary follicles and small secondary follicles were irregularly distributed. Growing follicles were found and larger follicles, less than 1 $\mathrm{cm}$ in diameter, showed typical changes of atresia. No CLs or corpora albicantia were present.
The cortical thickness increased from puberty attainment.

The usual organization into a cortical and a medullar ovarian zone was observed in all the goat ovaries throughout the reproductive cycle (Fig. 1a). The medullar zone had the usual highly vascular stroma, containing somewhere remnants of the rete ovarii (Fig. 1a, inset). In the cortical zone, it was possible to notice a variable amount of primary and secondary, non-cavitated follicles, which were not however considered in the histometric study. Multilaminar tertiary follicles $(\mathrm{N}=728)$ having an expanded antrum containing follicular fluid surrounded by layers of granulosa cells were recorded from proestrus to anestrus, with slightly different features in the different phases. Small follicles (Fig. 1b) were made of 

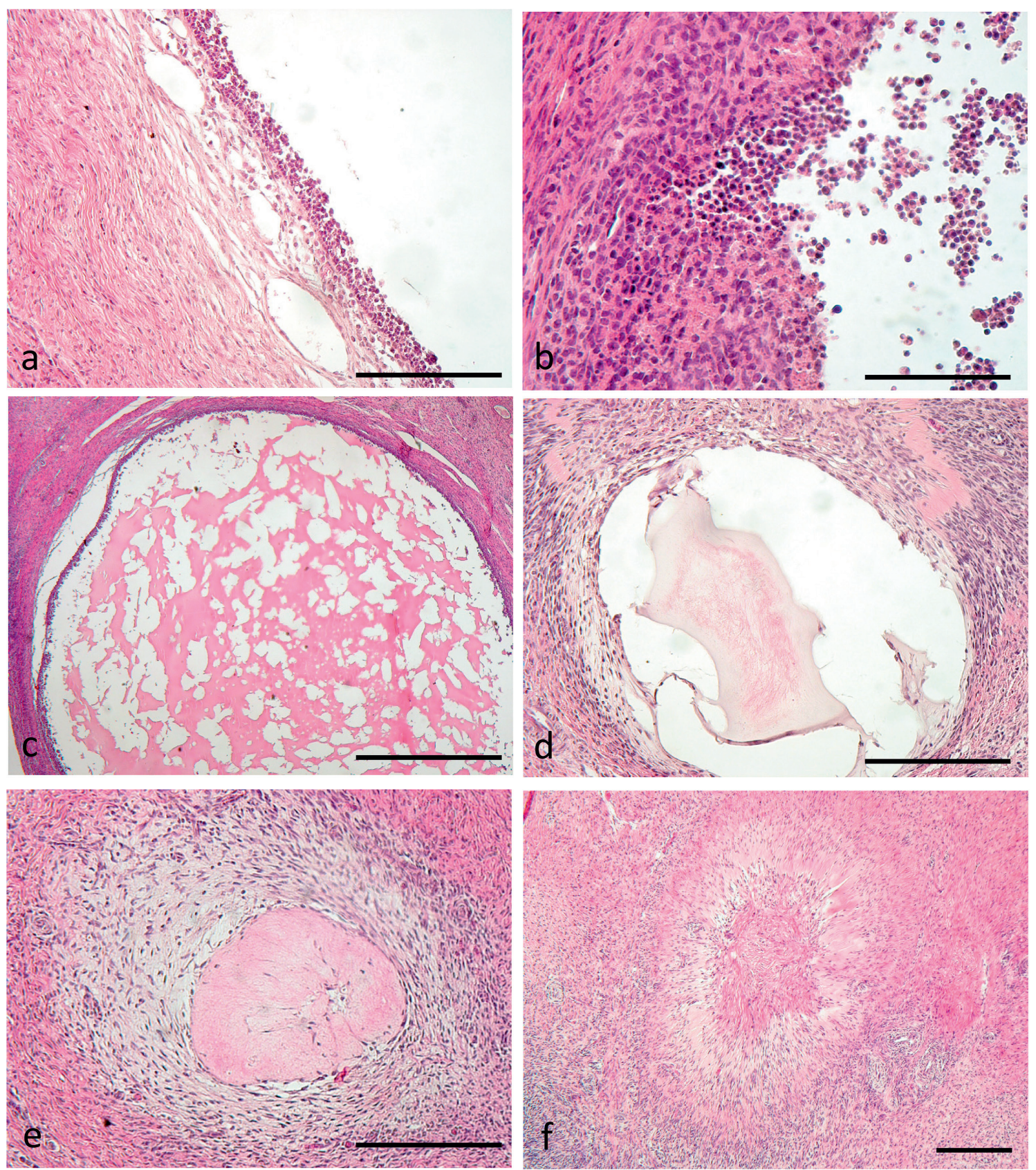

Figure 3. Progressive signs of follicular atresia can be seen during anestrus. Atretic follicle is loosely connected to the stroma (a) and various degrees of cellular degeneration can be seen in the granulosa and inner theca (b). At later stages of atresia colliquation of the liquor folliculi can be seen (c) together with wall degeneration (d) up to complete follicle obliteration (e) and connective substitution and cicatrization (f). Scale bars: a,d,e) $200 \mu \mathrm{m}$; b) $100 \mu \mathrm{m}$; c) 1000 $\mu \mathrm{m}$; d) $300 \mu \mathrm{m}$

10-14 layers of basophilic granulosa cells lying on a basal membrane, surrounded by an evident inner theca. Granulosa cells of the most superficial layer were small and round, those lying on the basal membrane were mostly columnar. The inner theca was characterized by fusiform cells (Fig. 1b, inset). Small follicles were also observed both during the periovulatory period and early diestrus, with many erythrocytes present into the surrounding stroma. Medium follicles (Fig. 1c) showed a thick stratum of granulosa cells and well developed inner theca, separated by an evident and somewhere loopy basal membrane. Many blood vessels could be seen around the follicle and 

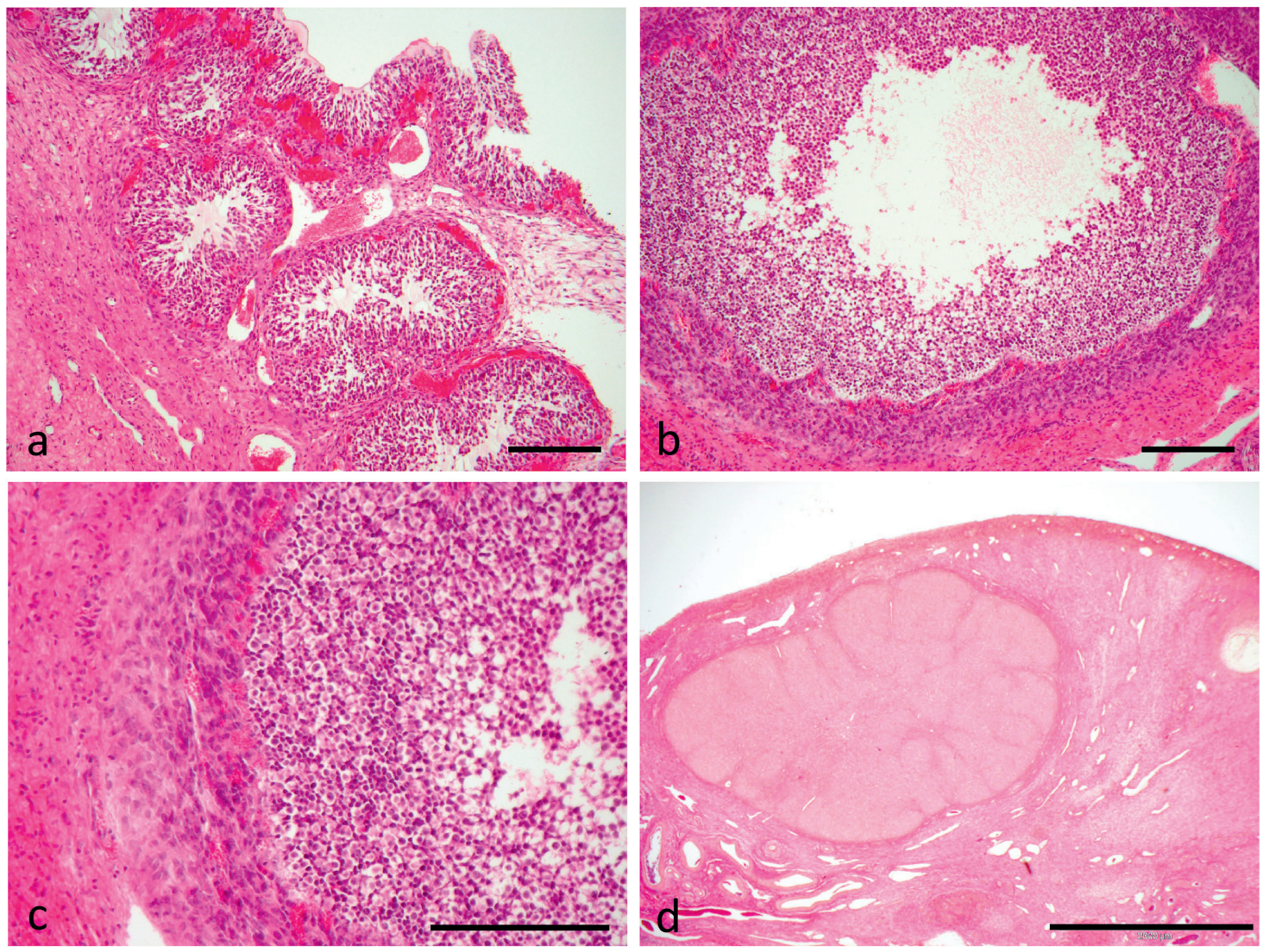

Figure 4. Morphology of a corpus hemorrhagicum (a) and progressive transformation (b, c) into a corpus luteum (d). Scale bars: a, b) $300 \mu \mathrm{m}$; c) 200 d) 2000

vascularizing the theca (Fig. 1c, inset). During anestrus, medium follicles were characterized by signs of atresia (Fig. 1d), i.e. detachment of the whole follicle from the surrounding stroma, granulosa cells loosely connected with each other, and theca cells having a swollen, disorganized or hypertrophic, somewhere fibroblast-like, aspect. The liquor folliculi showed a flocculated aspect and a mass of degenerating granulosa cells was often scattered into the antrum.

Large and very large follicles were noticed in all the periods of the ovarian cycle, including both prepubertal and cyclic anestrus. During prepubertal anestrus, large and even very large follicles showed well distinguishable granulosa and inner theca membranes, the latter well vascularized by a large number of capillaries (Fig. 2a). During proestrus the vascularization in the follicular inner theca was massive, especially in very large follicles (Fig. 2b), which often showed hypertrophic theca cells and folded granulosa. In the periovulatory period large follicles, coexisting with corpora hemorrhagica, showed flattened granulosa and theca membranes, with an indistinct boundary between them (Fig. 2c). During diestrus large and very large follicles were present, coexisting with large corpora lutea. Granulosa and theca membranes were well separated from each other and the inner theca was well vascularized (Fig. 2d). Large follicles in cyclic anestrus showed loose connections to the stroma, loss of blood vessels into the theca layer and various degrees of cellular (atretic) degeneration in the granulosa and inner theca.

During cyclic anestrus follicles at later stages of atresia were also observed, characterized by the disappearance of the follicular antrum, entirely occupied by degenerated cells from the granulosa and theca layers and somewhere a hyalinised aspect of the follicle remnants. Progressive signs of follicular atresia are described in Fig. 3.

Corpora hemorrhagica were characterized by the massive invasion of the theca capillaries into the granulosa, which protruded with large folds into the collapsed follicle, thus starting the obliteration of the follicular antrum (Fig. 4a, b, c). Corpora lutea constantly showed an obliterated aspect (Fig. 4d), being characterized by randomly 
distributed small and large luteal cells. Luteal cells showed accumulation of large amounts of lipids in their cytoplasm and were richly vascularized by the capillary network. No corpora albicantia (CA) were detected in any of the ovaries examined.

\section{Histometric outcomes of the ovarian structures}

Mean number and dimension of the ovarian structures at different stages of the reproductive cycle in our sample are shown in Table 1.

Table 1. Mean number and dimension of the ovarian structures through the phases of the reproductive cycle at the moment of slaughtering*

\begin{tabular}{|c|c|c|c|c|c|c|c|c|c|c|c|}
\hline & \multicolumn{4}{|c|}{ Number } & \multirow{2}{*}{$\begin{array}{c}\text { Size } \\
(\mathbf{m m})\end{array}$} & \multicolumn{2}{|c|}{ Number } & \multirow{2}{*}{$\begin{array}{c}\text { Size } \\
(\mathbf{m m})\end{array}$} & \multirow{2}{*}{$\begin{array}{c}\text { P4 } \\
(\mathrm{ng} / \mathrm{mL})\end{array}$} & \multirow{2}{*}{$\begin{array}{l}\text { BW } \\
(\mathrm{kg})\end{array}$} & \multirow{2}{*}{$\begin{array}{c}\text { Age } \\
\text { (days) }\end{array}$} \\
\hline & SF & MF & $\mathbf{L F}$ & XLF & & $\mathbf{C H}$ & $\mathbf{C L}$ & & & & \\
\hline Ap & $35.2 \pm 24.7$ & $7.2 \pm 13.9$ & $0.6 \pm 1.3$ & $0.4 \pm 0.9$ & $0.9 \pm 0.7$ & 0 & 0 & & $0.6 \pm 0.2$ & $14.5 \pm 6.8$ & $92.6 \pm 17.6$ \\
\hline $\mathbf{P}$ & $25.7 \pm 7.4$ & $5.2 \pm 2.5$ & $3.2 \pm 2.63$ & $2 \pm 1.4$ & $1.5 \pm 1.3$ & 0 & 0 & & $0.5 \pm 0.27$ & $26.9 \pm 3.3$ & $224 \pm 13.9$ \\
\hline $\mathbf{E}$ & $19.3 \pm 6.4$ & $3.3 \pm 1.5$ & $1.7 \pm 1.5$ & $0.7 \pm 1.1$ & $1.2 \pm 1$ & $1.3 \pm 0.6$ & 0 & $3.9 \pm 1.6$ & $1.3 \pm 0.2$ & $27.3 \pm 4$ & $154 \pm 115$ \\
\hline D & $15.1 \pm 7$ & $3.2 \pm 1.7$ & $3.1 \pm 1.5$ & $2 \pm 1$ & $1.8 \pm 1.5$ & 0 & $1.2 \pm 0.5$ & $8.4 \pm 3.3$ & $11.8 \pm 2.1$ & $32 \pm 2.3$ & $246.5 \pm 8.7$ \\
\hline $\mathbf{A}$ & $11.8 \pm 3.8$ & $2.6 \pm 1.5$ & $3.8 \pm 1.9$ & $2.4 \pm 1.1$ & $1.9 \pm 1.9$ & 0 & 0 & & $0.4 \pm 0.1$ & $33.2 \pm 3.3$ & $353.2 \pm 6.1$ \\
\hline $\begin{array}{l}\mathrm{SF}= \\
\mathrm{CH}= \\
\mathrm{P} 4= \\
\mathrm{Ap}= \\
\mathrm{BW}=\end{array}$ & $\begin{array}{l}\text { small follicle } \\
=\text { corpora her } \\
\text { plasma proge } \\
\text { prepubertal } \\
=\text { body weigh }\end{array}$ & $\begin{array}{l}\mathrm{s} ; \mathrm{MF}=\mathrm{med} \\
\text { norrhagica; } \\
\text { sterone conc } \\
\text { anestrus; } \mathrm{P}=\end{array}$ & $\begin{array}{l}\text { lium follicl } \\
\mathrm{CL}=\text { corpo } \\
\text { centration } \\
=\text { proestrus; }\end{array}$ & $\begin{array}{l}\text { es; } \mathrm{LF}=1 \mathrm{la} \\
\text { ra lutea } \\
\mathrm{E}=\text { estrus }\end{array}$ & rge follicle & $\mathrm{s} ; \mathrm{XLF}=$ & very large & follicles & & & \\
\hline
\end{tabular}

Table 2. Follicular number and type distribution throughout the different phases of the alpine goat reproductive cycle

\begin{tabular}{|c|c|c|c|c|c|c|}
\hline PHASE & SF & MF & LF & XLF & & TOTAL \\
\hline \multirow[t]{4}{*}{ Ap } & 176 & 36 & 3 & 2 & frequency & 217 \\
\hline & 24.18 & 4.95 & 0.41 & 0.27 & $\%$ total & 29.81 \\
\hline & 81.11 & 16.59 & 1.38 & 0.92 & $\%$ follicles & \\
\hline & 34.04 & 33.96 & 4.62 & 5 & $\%$ phase & \\
\hline \multirow[t]{4}{*}{$\mathbf{P}$} & 103 & 21 & 13 & 8 & frequency & 145 \\
\hline & 14.14 & 2.88 & 1.79 & 1,1 & $\%$ total & 19.92 \\
\hline & 71.03 & 14.48 & 8.97 & 5.52 & $\%$ follicles & \\
\hline & 19.92 & 19.81 & 20 & 20 & $\%$ phase & \\
\hline \multirow[t]{4}{*}{$\mathbf{E}$} & 58 & 10 & 5 & 2 & frequency & 75 \\
\hline & 7.97 & 1.37 & 0.69 & 0.27 & $\%$ total & 10.3 \\
\hline & 77.33 & 13.33 & 6.67 & 2.67 & $\%$ follicles & \\
\hline & 11.22 & 9.43 & 7.69 & 5 & $\%$ phase & \\
\hline \multirow[t]{4}{*}{ D } & 121 & 26 & 25 & 16 & frequency & 188 \\
\hline & 16.62 & 3.57 & 3.43 & 2.2 & $\%$ total & 25.82 \\
\hline & 64.36 & 13.83 & 13.3 & 8.51 & $\%$ follicles & \\
\hline & 23.4 & 24.53 & 38.46 & 40 & $\%$ phase & \\
\hline \multirow[t]{4}{*}{$\mathbf{A}$} & 59 & 13 & 19 & 12 & frequency & 103 \\
\hline & 8.1 & 1.79 & 2.61 & 1.65 & $\%$ total & 14.15 \\
\hline & 57.28 & 12.62 & 18.45 & 11.65 & $\%$ follicles & \\
\hline & 11.41 & 12.26 & 29.23 & 30 & $\%$ phase & \\
\hline \multirow[t]{2}{*}{ TOTAL } & 517 & 106 & 65 & 40 & frequency & 728 \\
\hline & 71.02 & 14.56 & 8.93 & 5.49 & $\%$ total & 100 \\
\hline
\end{tabular}

$\mathrm{Ap}=$ prepubertal anestrus; $\mathrm{P}=$ proestrus; $\mathrm{E}=$ estrus; $\mathrm{D}=$ diestrus; $\mathrm{A}=$ anestrus

$\mathrm{SF}=$ small follicles; $\mathrm{MF}=$ medium follicles; $\mathrm{LF}=$ large follicles; $\mathrm{XLF}=$ very large follicles 


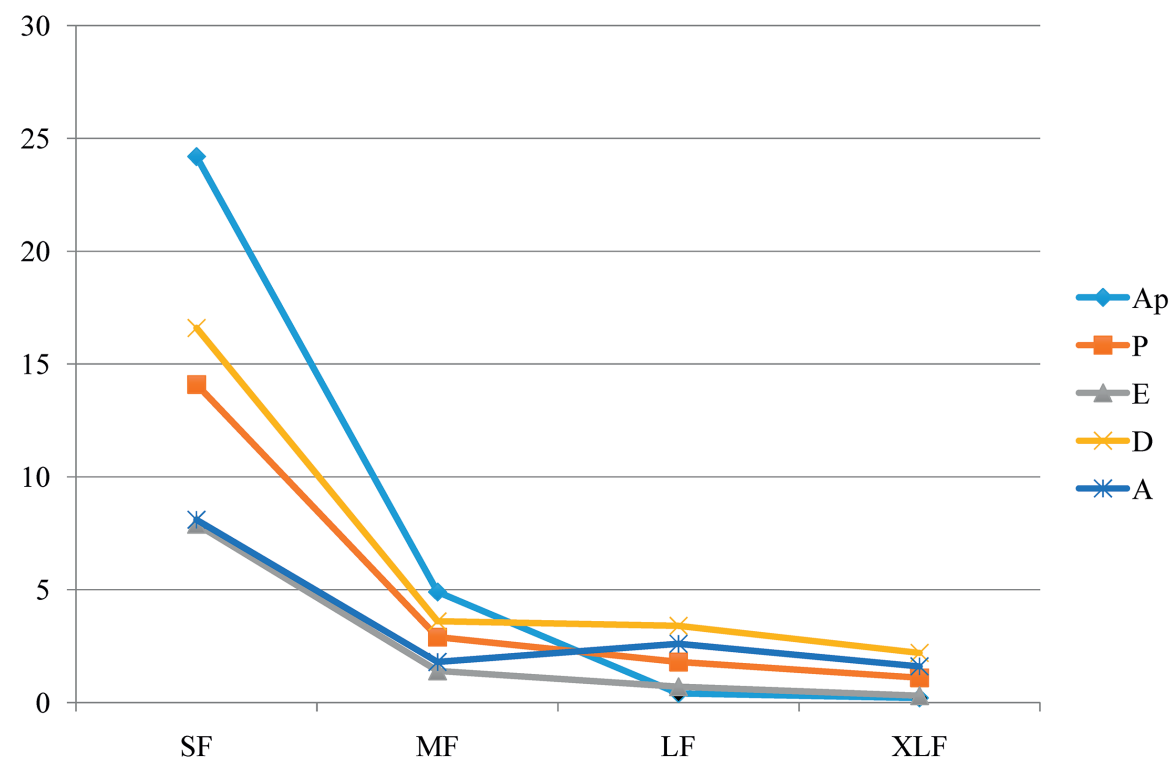

Figure 5. Distribution of follicles based on their size during the reproductive cycle. Ap = prepubertal anestrus; $\mathrm{P}$ = proestrus; $\mathrm{E}=$ oestrus; $\mathrm{D}=$ diestrus; $\mathrm{A}=$ anestrus; $\mathrm{SF}=$ small follicles; $\mathrm{MF}=$ medium follicles; $\mathrm{LF}=$ large follicles; $\mathrm{XLF}=$ very large follicles

The number of the follicles was influenced by the reproductive phase when variables (body weight and age) were considered together with $(\mathrm{P}<0.0001)$. The mean number of follicles were high during both prepubertal anestrus and diestrus, while it was low in oestrus (Table 2). However, the number of follicles was not statistically related with the reproductive phase when the same variables (body weight and age) were not deemed. Both these variables affected the number of follicles ( $\mathrm{P}<0.05)$, with body weight as the most relevant aspect $(\mathrm{P}=0.02)$. The mean diameter of the follicles was neither related with the reproductive phase nor to the age, while it was related with the body weight $(\mathrm{P}<0.0001)$. The mean diameter of the follicles was $1.48 \mathrm{~mm}$ with an increase of $0.063 \mathrm{~mm}$ for every $\mathrm{kg}$ gained in body weight, that is $\mathrm{b} \pm \mathrm{ES}=+0.063 \pm$ 0.012 ( $\mathrm{P}<0.0001)$. When the follicular dimensions were considered as categorical variables (small, medium, large and very large), they significantly differed among the phases of the reproductive cycle ( $\mathrm{P}<0.0001$, graph in Fig. 5). Namely, large and very large follicles $(\mathrm{P}<0.001)$, and small follicles $(\mathrm{P}<0.05)$ varied throughout the reproductive cycle, while medium follicles were invariably observed. Large and very large follicles were predominant during the diestrus phase and small follicles in the prepubertal anestrus.

\section{DISCUSSION}

Alpine goats are seasonally polyestrous animals with typically recurrent oestrous periods at about 21 day intervals when light hours per day decline (4), that is from September to February in Northern Italy where this study was conducted. Studies of ovarian activity during the reproductive cycle in goats are limited and mainly related to ultrasound monitoring. Even rarer are the studies of the natural reproductive cycle. To our knowledge, a detailed description of the morphology and size of the ovarian structures throughout the reproductive cycle in relation to the oestrus phase, the body weight and age has not been previously reported in goats.

It is nowadays admitted that follicular dynamics in goats exhibit a wave-like pattern, most frequently characterized by four waves (9). In the first follicular wave and in the ovulatory wave, the largest follicles exert dominance on the other coexistent follicles (9). During the follicular dominance, preovulatory follicular growth and maturation occur while the other follicles of the cohort complete regression by atresia. Part of the observed medium follicles might belong to the cohort of subordinate follicles. Follicular atresia affects all stages of follicular development, but the proportion of follicles that 
become atretic is enhanced by increased follicle size in woman (12). Follicular atresia in our sample was observed both during prepubertal and cyclic anestrus. Atretic follicles were characterized by detachment of the whole follicle from the surrounding stroma, granulosa cells loosely linked together, and theca cells having a bloated, unorganized or hypertrophic aspect, which in some places assumed a fibroblast-like appearance. Follicular dominance in goat is reported to be less absolute than in mono-ovulatory species such as cattle with two potential ovulatory follicles developing rather than one (13). In agreement with previous findings, we recorded an asymmetric distribution of the ovarian structures between the right and left ovary $(9,14)$. This asymmetry between ovaries could partially be related to some local effect involved in follicular dominance (9), whereas the presence of simultaneous, sometimes bilateral, very large follicles can result from different follicular waves. The phenomenon of follicular dominance may be also present, or not, in the middle of the luteal phase $(3,9)$. At this regard, it is interesting to note that large and very large follicles were predominant during the diestrus phase in our sample. These findings seem to confirm the presence of a dominant follicle in the luteal phase. It has been postulated that the large follicles observed in the mid to late luteal phases were not the follicles which ovulated at the subsequent oestrus (4). Due to the single withdrawal allowed by the histological approach, we cannot speculate on the dynamic development of such ovarian structures. There is evidence suggesting the presence of dominant follicles also before puberty in lambs (15). Similarly, we bilaterally observed large and very large follicles in one prepubertal anestrous goat (ID. 2), the heaviest ones.

A great variability in the onset and duration of each wave during the reproductive cycle is reported, as well as in the maximum size of the dominant follicle (9). This makes difficult to identify ovulatory follicles, which is important in breeding programs since the efficacy of hormonal treatments depends on the absence of dominant follicles (15). Periovulatory large follicles were characterized by flattened granulosa rich in blood capillaries, indistinguishable from theca membranes. The largest follicles recorded in this study measured $8.2 \mathrm{~mm}$.

Unlike sheep, the number and type of follicles in goats seems to be related to the stage of the reproductive cycle (7). During oestrus, the number of follicles was the lowest. Small follicles were present in greatest number during the prepubertal anestrus, medium follicles were invariably observed throughout the reproductive cycle, and large and very large follicles were predominant during the diestrus phase.

Nevertheless, the mean diameter of the follicles was neither related with the reproductive stage nor to the age, while it was related with the body weight. These data confirm the relation between body weight and sexual development as shown in many species, goats included. Indeed, the onset of puberty has been closely associated with body growth and nutritional rate rather than age (16).

Several studies in goats described progesterone profiles throughout the estrous cycle $(3,17,18)$. However, the correlation between follicular structure assessed by histo-morphometry and plasma progesterone concentrations is not available. Contrary to an early study in goats showing that the smallest follicles develop under continuous and high progesterone concentrations $(13,19)$, in the current study small follicles predominated during the reproductive phases characterized by low progesterone concentration, namely prepubertal anestrus.

CHs and CLs are temporary endocrine glands in mammals that develop from the remains of a follicle following ovulation (20). Histological descriptions of corpora hemorrhagica in goats are very rare. CHs described in our sample were characterized by a collapsed aspect of the follicle, wherein granulosa, massively invaded by the theca capillaries, protruded with large folds into the lumen, thus starting the obliteration of the follicular antrum. Previous studies that have been carried out in diverse breeds of goat in different regions of the world have found a positive correlation between CL diameter and progesterone concentration during the estrous cycle $(21,22,23,24)$. Furthermore, Simoes et al. (25) reported that plasma progesterone concentration was higher in goats with two CL in comparison with goats having only one CL (25). Even if the limited number of data does not allow statistically comparisons, the same trend was not observed in current sample. In agreement with our data, Arashiro et al. (26) suggested that luteal tissue growth is positively correlated with corpora lutea functionality, whereas luteal tissue area did not influence progesterone concentration (26). Namely, when corpus luteum reached its maximum size, the co-existence of one or more CL did not increase progesterone concentration (26). In goats, maximal plasma progesterone concentration has been related to the breed, with Saanen showing higher values than Alpine goats (27). 
Curiously we have not found corpora albicantia in any of the ovary examined. CA are described as white fibrous tissue that replaces the regressing corpus luteum approximately equal to 3-4 $\mathrm{mm}$ in diameter in ewes (28) and are also detected in goats (29). We can speculate that these structures are made evident in older goats after at least one anestrus phase. In the current sample, all animals have been slaughtered after the first anestrus.

\section{CONCLUSION}

The current study demonstrated the functional morphological and histological appraisal of the ovarian structures during different functional phases of the reproductive cycle in the Alpine goats in relation with age, body weight and progesterone concentration. These findings might be a valuable contribution to a deeper understanding of ovarian transformation with important implications in assisted reproductive technologies, thereby concurring in advancing the efficiency of ultrasound in breeding programs in this species.

\section{CONFLICT OF INTEREST STATEMENT}

The authors declared that they have no potential conflict of interest with respect to the authorship and/or publication of this article.

\section{ACKNOWLEDGEMENTS}

Authors wish to thank Dr. Mario Villa for sanitary supervision of the herd, Prof. Davide Pravettoni for the support in killing animals, Dr. Pietro Riccaboni for conducting the autopsies and helping during sample collection, Dr. Giampaolo Bosi for technical assistance in histology and histometry. Grant sponsor: GENHOME Project by the Italian Ministry of University and Research (MIUR), 2012.

\section{REFERENCES}

1. Groppetti, D., Aralla, M., Bronzo, V., Bosi, G., Pecile, A., Arrighi, S. (2015). Periovulatory time in the bitch: what's new to know: Comparison between ovarian histology and clinical features. Anim Reprod Sci. 152, 108-116.

https://doi.org/10.1016/j.anireprosci.2014.11.008 PMid:25510561
2. Amiridis, G.S., Cseh, S. (2012). Assisted reproductive technologies in the reproductive management of small ruminants. Anim Reprod Sci. 130, 152-161.

https://doi.org/10.1016/j.anireprosci.2012.01.009 PMid:22381207

3. Camp, J.C., Wildt, D.E., Howard, P.K., Stuart, L.D., Chakraborty, P.K. (1983). Ovarian activity during normal and abnormal length estrous cycles in the goat. Biol Reprod. 28, 673-681.

https://doi.org/10.1095/biolreprod28.3.673

PMid:6221766

4. de Castro, T., Rubianes, E., Menchaca, A., Rivero, A. (1999). Ovarian dynamics, serum estradiol and progesterone concentrations during the interovulatory interval in goats. Theriogenology 52 , 399-411.

https://doi.org/10.1016/S0093-691X(99)00138-7

5. Gonzalez-Bulnes, A., Pallares, P., Vazquez, M.I. (2010). Ultrasonographic imaging in small ruminant reproduction. Reprod Domest Anim. 45 Suppl 2, 9-20.

https://doi.org/10.1111/j.1439-0531.2010.01640.x PMid:20591060

6. Mohammadi, G., Kohram, H., Gooraninejad, S., Yousefi, A., Motaghedi, A. (2010). Ovarian follicular dynamics during the interovulatory interval in Najdi goats. African Journal of Biotechnology 9, 5236-5239.

7. Evans, A.C.O. (2003). Characteristics of ovarian follicle development in domestic animals. Reprod Dom Anim. 38, 240-246.

https://doi.org/10.1046/j.1439-0531.2003.00439.x

8. Zarkawi, M., Soukouti, A. (2001). Serum progesterone levels using radioimmunoassay during oestrus cycle of indigenous Damascus does. New Zealand Journal of Agricultural Research 44, 165-169. https://doi.org/10.1080/00288233.2001.9513473

9. Simoes, J., Almeida, J.C., Valentim, R., Baril, G., Azevedo, J., Fontes, P., Mascarenhas, R. (2006). Follicular dynamics in Serrana goats. Animal Reproduction Science 95, 16-26.

https://doi.org/10.1016/j.anireprosci.2005.09.005

PMid:16226410

10. Farshad, A., Akhondzadeh, S., Zamiri, M.J., Sadeghi, G.H. (2008). The estrous cycle of the Markhoz goat in Iran. Asian-Aust J Anim Sci. 21, 1411-1415.

https://doi.org/10.5713/ajas.2008.70707 
11. Brugger, N., Otzdorff, C., Walter, B., Hoffmann, B., Braun, L. (2011). Quantitative determination of progesterone (P4) in canine blood serum using an enzyme-linked fluorescence assay. Reprod. Dom. Anim. 46, 870-873.

https://doi.org/10.1111/j.1439-0531.2011.01757.x PMid:21323757

12. Kaipia, A., Hsueh, A.J.W. (1997). Regulation of ovarian follicle atresia. Annu Rev Physiol. 59, 349-363. https://doi.org/10.1146/annurev.physiol.59.1.349 PMid:9074768

13. Rubianes, E., Menchaca, A. (2003). The pattern and manipulation of ovarian follicular growth in goats. Animal Reproduction Science 78, 271-287. https://doi.org/10.1016/S0378-4320(03)00095-2

14. Geres, D., Zevrnja, B., Zubcic, D.,Zobel, R., Vulic, B., Staklarevic, N., Gracin, K. (2011). Asymmetrical functional activities of ovaries and tubular part of reproductive organs of dairy cows. Veterinarski archiv 8, 187-198.

15. Driancourt, M.A. (2001). Regulation of ovarian follicular dynamics in farm animals. Implications for manipulation of reproduction. Theriogenology 55, 1211-1239.

https://doi.org/10.1016/S0093-691X(01)00479-4

16. Sakurai, K., Ohkura, S., Matsuyama, S., Katoh, K., Obara, Y., Okamura, H. (2004). Body growth and plasma concentrations of metabolites and metabolic hormones during the pubertal period in female Shiba goats. Journal of Reproduction and Development 50, 197-205.

https://doi.org/10.1262/jrd.50.197

17. Bono, G., Cairoli, F., Tamanini, C., Abrate, L. (1983). Progesterone, estrogen, LH, FSH and PRL concentrations in plasma during the estrous cycle in goat. Reprod Nutr Develop. 23, 217-222.

https://doi.org/10.1051/rnd:19830206

18. Medan, M.S., Watanabe, G., Sasaki, K., Groome, N.P., Sharawy, S., Taya, K. (2005). Follicular and hormonal dynamics during the estrous cycle in goats. Journal of Reproduction and Development 51, 455-463.

https://doi.org/10.1262/jrd.17017

19. Ginther, O.J., Kot, K. (1994). Follicular dynamics during the ovulatory season in goats. Theriogenology 42, 987-1001.

https://doi.org/10.1016/0093-691X(94)90121-X
20. Wang, Z., Chen, S., Mo, H., Huang, Y., Li, J., Sun, J., Liu, L., Zhao, S. (2013). A simple and economical method in purifying dairy goat luteal cells. Tissue Cell 45, 269-274.

https://doi.org/10.1016/j.tice.2013.03.004

PMid:23639766

21. Orita, J., Tanaka, T., Kamomae, H., Kaneda, Y. (2000). Ultrasonographic observation of follicular and luteal dynamics during the estrus cycle in Shiba goats. J Reprod Dev. 46, 31-37.

https://doi.org/10.1262/jrd.46.31

22. Medan, M.S., Watanabe, G., Sasaki, K., Sharawy, S., Groome, N.P., Taya, K. (2003). Ovarian dynamics and their associations with peripheral concentrations of gonadotropins, ovarian steroids, and inhibin during the estrous cycle in goats. Biology of Reproduction 69, 57-63.

https://doi.org/10.1095/biolreprod.102.013334

PMid:12606405

23. Chao, L.M., Takayama, K., Nakanishi, Y., Hamana, K., Takagi, M., Kubota, C., Kojima, T. (2008). Luteal lifespan and fertility after estrus synchronization in goats. J Vet Sci. 9, 95-101.

https://doi.org/10.4142/jvs.2008.9.1.95

PMid:18303279 PMCid:PMC2839119

24. Bukar, M.M., Rosnina, Y., Ariff, O.M., Wahid, H., Mohd Azam Khan, G.K., Yimer, N., Dhaliwal, G.K. (2012). Corpora lutea diameter, plasma progesterone concentration and follicular development in PGF $2 \alpha$ and CIDR estrus synchronized goats. Pakistan Veterinary Journal 32, 216-220.

25. Simoes, J., Almeida, J.C., Baril, G., Azevedo, J., Fontes, P., Mascarenhas, R. (2007). Assessment of luteal function by ultrasonographic appearance and measurement of corpora lutea in goats. Animal Reproduction Science 97, 36-46.

https://doi.org/10.1016/j.anireprosci.2006.01.006 PMid:16481133

26. Arashiro, E.K.N., Viana, J.H.M., da Fonseca, J.F., de Almeida Camargo, L.S., de Carvalho Fernandes, C.A., Brandão, F.Z. (2010). Luteal dynamics in goats: morphological and endocrine features. Revista Brasileira de Zootecnia 39, 1937-1942. https://doi.org/10.1590/S1516-35982010000900011

27. Fonseca, J.F., Torres, C.A.A. (2005). Administration of hCG 5 days after breeding and reproductive performance in nulliparous dairy goats. Reproduction in Domestic Animals 40, 495-499. https://doi.org/10.1111/j.1439-0531.2005.00612.x PMid:16324072 
28. O'Shea, J.D., Wright, P.J. (1985). Regression of the corpus luteum of pregnancy following parturition in the ewe. Acta Anat (Basel). 122, 69-76.

https://doi.org/10.1159/000145985
29. de Moura, M.T.M.M., da Fonseca, V.U., da Silva, N.B., de Lourdes Freitas, M., de Almeida, O.B., de Oliveira Rocha, H.A., de Carvalho Papa, P., de Moura, C.E.B. (2010). Morphological features and vascularization study of caprine cyclic corpus luteum. Pesquisa Veterinaria Brasileira 30, 351-357. https://doi.org/10.1590/S0100-736X2010000400012

Please cite this article as: Groppetti D., Pecile A., Frattini S., Pagnacco G., Arrighi S. Histological feature of ovarian structures throughout the reproductive cycle in alpine goats (Capra hircus). Mac Vet Rev 2019; 42 (1): 23-34.

https://doi.org/10.2478/macvetrev-2018-0027 